\title{
PEMANFAATAN SERBUK GERGAJI SEBAGAI SUBSTITUSI BAHAN BAKAR PADA PROSES PEMBAKARAN - KILN DI PABRIK SEMEN DENGAN PENDEKATAN LIFE CYCLE ASSESMENT (LCA)
}

\section{Utilization of Saw Dust as Substitution Fuel at Combustion Process - Kiln at Cement Plant Using Life Cycle Assesment (LCA) Approach}

\author{
Ahmad Zaky Nugraha ${ }^{\mathrm{a}}$, Edi Iswanto Wiloso ${ }^{\mathrm{b}}$, Mohammad Yani ${ }^{\mathrm{c}}$ \\ ${ }^{a}$ Sekolah Pascasarjana, Institut Pertanian Bogor, Kampus IPB Dramaga, Bogor 16680 \\ -ahmadzaky.nugraha@yahoo.com \\ ${ }^{b}$ Pusat Penelitian Kimia LIPI, Puspiptek Serpong, Tanggerang Selatan 15314 \\ ${ }^{c}$ Departemen Teknologi Industri Pertanian Bogor, FakultasTeknologi Pertanian, Institut Pertanian Bogor, Kampus \\ IPB Darmaga, Bogor 16680
}

\begin{abstract}
Cement production was a process that requires huge thermal energy and produces high greenhouse gas emissions. Coprocessing or utilising alternative materials and alternative fuels for the combustion process in kiln was a solution to meet energy needs and reduce greenhouse gas emissions in the cement industry. This study aimed to analyze input, output, environmental impacts of cement production and calculate $\mathrm{CO}_{2}$-eq reduction from the system used alternative fuels on co-processing. The method used to determine differences and calculate $\mathrm{CO}_{2}$-eq reduction due to co-processing was life cycle assessment (LCA) and system approach. Based on the results of the LCA, the case 1 that used 100\% coal energy required $3.50 \mathrm{GJ} /$ ton-cement, $126 \mathrm{kWh} / \mathrm{ton}$ cement, $2.19 \mathrm{~L}$-diesel-oil/ton of cement and emited 0.84 ton-CO2-eq/ton-cement. Case 2 that had been substituted alternative fuels (saw dust) required $3.03 \mathrm{GJ}$ per ton of cement, $118 \mathrm{kWh}$ per ton of cement, $1.44 \mathrm{~L}$ diesel oil per ton of cement and emited 0.92 ton$\mathrm{CO}_{2}$-eq per ton of cement. The results of global warming impact of case 2 was higher than case 1. The assumption of climate neutral made reduction global warming impact of case 2 by $14.65 \%$ and decrease $\mathrm{CO}_{2}$ emissions annually in plant by 71,601 tons $\mathrm{CO}_{2} /$ year. This result show that utilization of saw dust as biomass of climate neutral can be applied as an input for overall company specific emissions calculation to meet government regulation.
\end{abstract}

Keywords: Cement, emission reduction, life cycle assessment, saw dust.

(Diterima: 11-08-2017; Disetujui: 05-10-2017)

\section{Pendahuluan}

\subsection{Latar Belakang}

Semen adalah agen perekat yang penting untuk industri konstruksi dan diproduksi dalam jumlah yang besar di dunia. Proses produksi semen adalah proses yang membutuhkan energi termal yang besar. Sekitar $40 \%$ dari keseluruhan biaya operasional pada industri semen dihabiskan untuk pengadaan energi. Bahan bakar fosil, seperti batubara secara umum telah digunakan sebagai sumber energi dalam industri semen (Harjanto et al., 2012). Tingginya tingkat produksi semen memiliki potensi pencemaran yang dapat menganggu masyarakat di sekitar wilayah industri tersebut karena penggunaan sumberdaya alam yang besar (Lestari, 2010). Dampak lingkungan utama dari industri semen karena penggunaan energi yang tinggi adalah emisi udara terutama emisi $\mathrm{CO}_{2}$ yang berpengaruh pada perubahan iklim (Guereca et al. 2012; Stafford 2015). Industri semen diperkirakan menyumbang sebesar 5-7\% emisi gas $\mathrm{CO}_{2}$ di dunia (Hasanbeigi et al., 2012; Reza et al., 2013; Stafford et al., 2015). Besarnya emisi yang dikeluarkan oleh industri semen disebabkan oleh tingginya produksi dan permintaan semen di seluruh dunia yang diprediksikan akan terus meningkat (Hasanbeigi et al., 2012). Saat ini, pemerintah Indonesia telah memiliki komitmen untuk menurunkan emisi gas rumah kaca sebesar $26 \%$ dengan usaha sendiri dan $41 \%$ dengan bantuan internasional yang telah tertulis dalam Peraturan Presiden Nomor 61 Tahun 2011 tentang Rencana Aksi Nasional Penurunan Emisi Gas Rumah Kaca (Setkab RI, 2011).

Perpres Nomor 61 Tahun 2011 berisi tentang institusi-institusi yang bertanggung jawab terhadap target penurunan emisi GRK nasional, arahan kebijakan setiap sektor, dan aksi-aksi mitigasi yang mungkin dapat dilaksanakan untuk mencapai target penurunan emisi GRK nasional (ASI, 2014). Berdasarkan perpres tersebut target penurunan GRK meliputi 6 bidang yaitu, bidang pertanian, kehutanan dan lahan gambut, energi dan transportasi, industri, pengelolaan limbah dan kegiatan pendukung lainnya. Sektor industri memiliki target penurunan sebesar 0.001 Gton- $\mathrm{CO}_{2}$-eq pada skenario $26 \%$ dan sebesar 0.005 Gton- $\mathrm{CO}_{2}$-eq pada skenario $41 \%$. Dalam sektor industri terdapat 8 sub-sektor industri yang memberikan kontribusi pada emisi GRK, yaitu industri semen $(27.97 \%)$, industri besi dan baja (7.29\%), industri pulp dan kertas $(27.11 \%)$, industri tekstil $(9.69 \%)$, industri petrokimia $(10.02 \%)$, industri keramik (1.19\%), industri pupuk $(9.82 \%)$, serta industri makanan dan minuman $(6.91 \%)$. Industri semen merupakan subsektor penyumbang emisi GRK tertinggi dalam bidang industri (Kemenperin, 2012a). Untuk mendukung penurunan emisi GRK yang ada pada industri semen telah diterbitkan Peraturan Menteri 
Perindustrian Nomor 12 tahun 2012 tentang Peta Panduan (Roadmap) Pengurangan Emisi $\mathrm{CO}_{2}$ Industri Semen di Indonesia. Pada peraturan tersebut industri semen diharapkan dapat menurunkan secara sukarela emisi $\mathrm{CO}_{2}$ yang dihasilkan sebesar $2 \%$ untuk kurun waktu 2011-2015 dan secara wajib sebesar 3\% untuk kurun waktu 2016-2020 (Kemenperin, 2012b).

Salah satu upaya untuk memenuhi kebutuhan energi dan menurunkan emisi gas rumah kaca yang ada dalam industri semen adalah co-processing. Co-processing adalah penggunaan bahan bakar dan material alternatif dalam industri semen. Co-processing diharapkan dapat menjadi solusi penyediaan energi dan pengurangan emisi $\mathrm{CO}_{2}$ yang ada di industri semen. Co-processing telah terbukti mengurangi dampak lingkungan yang dihasilkan dalam industri semen dan menghemat biaya bagi industri semen (Guereca et al., 2012; Hasanbeigi et al., 2012; Baidya et al., 2016). Selain itu, coprocessing merupakan solusi hemat biaya dan ramah lingkungan dalam penanganan limbah yang dapat membahayakan lingkungan serta telah diterapkan di berbagai negara maju (Li et al., 2012; Hasanbeigi et al., 2012; Reza et al., 2013). Co-processing diharapkan dapat menghilangkan permasalahan lingkungan dari pengelolaan limbah di masyarakat dan menjadi solusi pemenuhan energi yang ada di industri semen.

Co-processing merupakan salah satu upaya penurunan emisi gas rumah kaca di industri semen dalam Permen Perindustrian Nomor 12 Tahun 2012. Contoh bahan bakar alternatif yang digunakan untuk kegiatan co-processing adalah biomasa, refuse derived fuel (RDF) (Guereca et al., 2012), sampah perkotaan (Hasanbeigi et al., 2012; Reza et al., 2013), limbah lumpur (Hasanbeigi et al., 2012; Baidya et al., 2016), oli bekas, plastik, limbah kertas, dan ban bekas (Baidya et al., 2016). Jenis bahan bakar alternatif lainnya masih sangat mungkin untuk digunakan dalam co-processing. Pemanfaatan limbah sebagai sumber bahan bakar alternatif dapat menjadi solusi yang sangat baik bagi penyediaan energi yang ramah lingkungan. Coprocessing dapat melestarikan sumber daya alam yang tidak terbarukan, reduksi limbah dan reduksi emisi yang menguntungkan secara lingkungan. Coprocessing dapat menjadi solusi pengelolaan limbah di masyarakat yang selama ini menjadi masalah karena limbah yang dibuang di tempat terbuka dan tidak dimanfaatkan. Pengelolaan limbah seperti itu dapat menyebabkan masalah lingkungan dan sosial di masyarakat. Selain menguntungkan secara lingkungan dan sosial untuk masyarakat, penggunaan material dan bahan bakar alternatif pada industri semen dapat memberikan dampak pada berkurangnya biaya produksi yang dapat menguntungkan secara ekonomi.

Selain dampak positif, aktivitas co-processing dikhawatirkan dapat menimbulkan dampak negatif yang membuat permasalahan baru. Permasalahan tersebut berkaitan tentang besarnya konstribusi emisi dan kemungkinan dampak lingkungan baru yang dihasilkan oleh penggunaan material dan bahan bakar alternatif dalam industri semen (Harjanto et al., 2012). Pelaksanaan co-processing tanpa perhitungan yang baik dikhawatirkan dapat menimbulkan dampak negatif pada lingkungan. Hal ini dikarenaan limbah atau biomassa yang digunakan dapat mengandung bahan berbahaya dan beracun (B3) sehingga dalam pengelolaan limbah B3 diperlukan peraturan dan izin khusus agar tidak menyebabkan kerusakan lingkungan. Proses perhitungan secara menyeluruh dan mendalam perlu dilakukan pada proses co-processing. Proses perhitungan dilaksanakan agar dapat diketahui dampak yang ditimbulkan sesudah dan sebelum co-processing dilakukan sehingga dampak baru yang ditimbulkan dapat teridentifikasi dan terkuantifikasi dengan baik.

Proses perhitungan dampak pada co-processing dapat dilaksanakan menggunakan metode life cycle assessment (LCA) untuk mengetahui perbedaan dampak yang ditimbulkan sesudah dan sebelum dilakukannya co-processing. Life Cycle Assessment (LCA) merupakan sebuah metode berbasis cradle to grave yang digunakan untuk mengetahui jumlah material, energi, dan dampak lingkungan yang disebabkan oleh tahapan daur hidup produk dimulai dari saat pengambilan bahan baku sampai dengan produk itu selesai digunakan oleh konsumen (Harjanto et al., 2012). LCA mulai dikenal secara luas sekitar 20 tahun yang lalu. Hal ini dapat terlihat dari penggunaan dan penerapan LCA telah pada berbagai bidang yang dilakukan oleh pihak pemerintah dan swasta untuk pengambilan keputusan. Peningkatan aplikasi LCA terjadi dikarenakan adanya standar yang telah berlaku secara internasional (Finkbeiner, 2016). Pada tahun 2006 telah diterbitkan dua standar baru terkait LCA, yaitu ISO 14040 dan ISO 14044. Kedua standar ini menggantikan empat standar yang telah ada sebelumnya yaitu ISO 14040:1997, ISO 14041:1999, ISO 14042:2000 dan ISO 14043:2000 (Finkbeiner et al 2006). Manfaat LCA diharapkan dapat menjadi sumber informasi jumlah kontribusi dan penurunan dampak pemanasan global yang terjadi melalui co-processing untuk memenuhi peraturan yang ada.

\subsection{Tujuan}

Penelitian ini dilakukan dengan tujuan untuk menentukan dan membandingkan besaran energi listrik, energi panas, solar dan dampak pemanasan global per ton semen yang dihasilkan pada produksi semen yang menggunakan energi batubara $100 \%$ dan yang telah disubtitusi bahan bakar alternatif (saw dust) melalui co-processing serta menganalisis penurunan emisi gas rumah kaca di plant berdasarkan penggunaan bahan bakar alternatif.

\section{Metode}

\subsection{Tahapan Penelitian}

Metode LCA dilakukan berdasarkan principles and framework LCA yang ada pada ISO 14040 yang dikeluarkan tahun 2006. Tahapan LCA terdiri dari 4 tahap, yaitu penentuan tujuan dan ruang lingkup (goal and scope definition), analisis inventarisasi input dan 
output (life cycle inventory analysis), penilaian dampak lingkungan dari data inventori (life cycle impact assessment), dan interpretasi hasil (life cycle interpretation) (ISO, 2006). Selanjutnya untuk menghitung penurunan emisi gas rumah kaca menggunakan pendekatan sistem berdasarkan data LCA yang didapatkan.

\subsection{Penentuan Tujuan dan Ruang Lingkup LCA (Goal and Scope Definition)}

Goal and scope definition merupakan tahap awal dalam melakukan analisis LCA. Pada tahap ini akan dibuat dan ditentukan tujuan dari kajian LCA yang akan dilakukan serta menentukan batasan atau ruang lingkup yang akan dikaji dalam pelaksanaan LCA. Goal and scope definition yang baik akan membuat kajian LCA yang dilakukan lebih sistematis dan terarah. Pada studi LCA akan dilihat perbandingan kasus penggunaan energi pada produksi semen, yaitu melalui penggunaan batubara $100 \%$ dan yang telah disubtitusi bahan bakar alternatif (saw dust) pada coprocessing. Pembatasan yang dilakukan pada LCA yang dilakukan akan menggunakan pembatasan cradle to gate dengan functional unit 1 ton semen yang dihasilkan.

\subsection{Analisis Inventori Daur Hidup (Life Cycle Inventory)}

Data yang digunakan dalam penelitian ini berasal dari berbagai data, seperti pengamatan dan pengambilan data di plant, dokumen perusahaan serta data yang berasal dari publikasi ilmiah melalui studi literatur. Sebagian data lainnya diperoleh dari hasil perhitungan dan hasil pengolahan data primer serta estimasi data. Estimasi dilakukan untuk melengkapi nilai yang tidak diperoleh dari hasil pengumpulan dan pengolahan data. Berikut beberapa asumsi dan data yang digunakan dalam mengestimasi data untuk pembuatan inventori LCA dari kedua sistem yang dibandingkan.

\section{a. Data Penambangan Batu Kapur dan Tanah Liat}

Batukapur dan tanah liat merupaka bahan baku utama dalam proses produksi semen. Batu kapur dan tanah liat didapatkan dari proses penambangan. Jumlah penggunaan energi pada proses penambangan dapat diketahui menggunakan literatur yang ada. Pada Tabel 1 dapat dilihat penggunaan energi yang diperlukan dalam setiap aktivitas penambangan. Data energi yang diperoleh akan dirubah menjadi solar sebagai sumber energi alat-alat yang digunakan untuk menambang. Aktivitas penambangan menggunakan dua macam jenis energi, yaitu energi dari solar dan energi listrik. Energi listrik digunakan pada saat proses penggilingan sedangkan pada proses lainnya menggunakan energi dari solar untuk bahan bakar kendaraan.
Tabel 1. Kebutuhan energi aktivitas penambangan batu kapur dan tanah liat

\begin{tabular}{lc}
\hline \multicolumn{1}{c}{ Aktivitas } & Energi Spesifik (kWh/ton) ${ }^{1}$ \\
\hline Penggalian dan Peledakan & $0.1-0.25$ \\
Pengangkutan & $0.2-0.5$ \\
Penggilingan & $1-2$ \\
\hline &
\end{tabular}

\section{b. Data Pengadaan Batubara}

Pada proses pengadaan batubara dilakukan dari tahap penambangan, pengiriman dari pelabuhan, transportasi darat dan pengolahan (coal mill) di pabrik. Tambang batubara berada di pulau yang berbeda dengan plant yang ada di Pulau Jawa. Menurut Khohar (2013), pada proses penambangan batu bara terdiri dari pengerukan batubara, pemuatan batubara ke truk, transportasi oleh truk dan pengiriman batubara ke pelabuhan melalui conveyor. Selanjutnya batu bara dikirim dari pelabuhan di Pulau Jawa menuju plant. Estimasi waktu pengiriman batubara menggunakan kapal tongkang dengan muatan 6,000 ton adalah 10 hari. Menurut Talahatu dan Abdullah (2013), konsumsi bahan bakar untuk kapal tongkang jenis tersebut sebesar 3,000 L-solar/hari. Penggunaan energi pada pengadaan batubara dapat dilihat pada Tabel 2. Setelah mendarat di pelabuhan batubara akan dikirim melalui jalur darat menggunakan truk menuju plant.

Tabel 2. Kebutuhan energi spesifik pengadaan batubara

\begin{tabular}{ll}
\hline \multicolumn{1}{c}{ Aktivitas } & \multicolumn{1}{c}{ Energi } \\
\hline Penambangan batubara & 3.01 liter solar/ton ${ }^{1}$ \\
& $0.85 \mathrm{kWh} /$ ton $^{1}$ \\
Transportasi Laut & 5.00 liter solar/ton ${ }^{2}$ \\
\hline${ }^{1}$ Khohar (2013) & \\
${ }^{2}$ Talahatu dan Abdullah (2013) &
\end{tabular}

\section{c. Kebutuhan Solar Penyediaan Alternative Fuel (saw dust) dan Batubara}

Saw dust dan batubara yang digunakan untuk proses pembakaran di kiln berasal dari wilayah yang berbeda. Tahap pertama yang dilakukan adalah mengidentifikasi asal wilayah AF dan batubara untuk mengetahui jarak antara sumber limbah dan lokasi pabrik. Setelah mengetahui jarak antara asal sumber bahan bakar dan plant maka akan diketahui kebutuhan solar dan emisi gas rumah kaca yang dikeluarkan pada proses transportasi. Menurut Setiawati et al. (2015), kebutuhan solar untuk truk pengangkut dengan muatan sekitar 30 ton adalah $3.5 \mathrm{~km} / \mathrm{L}$. Untuk daerah asal saw dust berada di Pulau Jawa sedangkan batubara berasal dari Pulau Kalimantan sehingga untuk pengiriman batubara memerlukan transportasi melalui laut menggunakan kapal tongkang.

\section{d. Estimasi Dampak Pemanasan Global}

Proses estimasi dampak pemanasan global dilakukan pada proses yang tidak memiliki data pencatatan emisi. Pada proses estimasi dampak pemanasan global dilakukan berdasarkan data dari penggunaan energi seperti listrik dan penggunaan solar untuk bahan bakar yang dapat menghasikan gas rumah kaca. Solar 
digunakan untuk menggerakan berbagai kendaraan baik untuk proses produksi ataupun proses transportasi darat dan laut. Perbedaan nilai emisi gas rumah kaca pada transportasi darat dan laut dikarenakan adanya perbedaan tipe mesin antara kendaraan di darat dan kapal di laut. Untuk proses penambangan batubara proses estimasi berdasarkan pada inventarisasi gas rumah kaca yang dihitung berdasarkan per-ton batubara yang dihasilkan. Emisi gas rumah kaca saat penambangan batubara berbeda dengan pasca penambangan batubara. Emisi gas rumah kaca saat penambangan, yaitu emisi gas rumah kaca yang berasal dari gas tersimpan yang terbebas saat proses penambangan batubara sedangkan emisi gas rumah kaca pasca penambangan, yaitu emisi gas rumah kaca yang berasal pada saat penanganan, pemrosesan, dan transportasi batubara (KLH, 2012). Nilai konversi GRK dari penggunaan energi dapat dilihat di Tabel 2. Selanjutnya gas-gas rumah kaca akan dikonversi menjadi nilai $\mathrm{CO}_{2}$-eq yang menyatakan potensi pemanasan global. Nilai faktor emisi masing-masing GRK dapat dilihat pada Tabel 3.

Tabel 3. Faktor emisi GRK penggunaan energi

\begin{tabular}{|c|c|}
\hline Jenis Energi (unit) & Faktor Emisi \\
\hline Energi Listrik Jawa ${ }^{1}(\mathrm{kWh})$ & $0.84 \mathrm{~kg} \mathrm{CO} / \mathrm{kWh}$ \\
\hline \multirow[t]{2}{*}{ Solar Transportasi Darat ${ }^{2}(\mathrm{~L})$} & $2.66 \mathrm{~kg} \mathrm{CO}_{2} / \mathrm{L}$ \\
\hline & $\begin{array}{l}0.14 \times 10^{-3} \mathrm{~kg} \mathrm{CH}_{4} / \mathrm{L} \\
0.14 \times 10^{-3} \mathrm{~kg} \mathrm{~N}_{2} \mathrm{O} / \mathrm{L}\end{array}$ \\
\hline \multirow[t]{3}{*}{ Solar Transportasi Laut ${ }^{2}(\mathrm{~L})$} & $2.66 \mathrm{~kg} \mathrm{CO}_{2} / \mathrm{L}$ \\
\hline & $2.52 \times 10^{-3} \mathrm{~kg} \mathrm{CH}_{4} / \mathrm{L}$ \\
\hline & $0.72 \times 10^{-3} \mathrm{~kg} \mathrm{~N}_{2} \mathrm{O} / \mathrm{L}$ \\
\hline Batubara Operasi ${ }^{2}$ (ton) & $8.04 \times 10-{ }^{2} \mathrm{~kg} \mathrm{CH}_{4} /$ ton \\
\hline Batubara Pasca Operasi ${ }^{2}$ (ton) & $0.67 \times 10^{-1} \mathrm{~kg} \mathrm{CH}_{4} / \mathrm{ton}$ \\
\hline ESDM (2016) & \\
\hline
\end{tabular}

\subsection{Penilaian Dampak Lingkungan (Life Cycle Impact Assesment)}

Penilaian dampak lingkungan dilakukan untuk mengevaluasi dampak yang dihasilkan berdasarkan hasil analisis inventori. Tahap pertama yang dilakukan pada penilaian dampak lingkungan adalah pemilihan kategori dampak, kategori indikator dan model karakterisasi dampak yang ada. Kategori dampak yang akan diperhatikan pada studi LCA ini adalah dampak pemanasan global dengan indikator $\mathrm{CO}_{2}$-eq yang berasal dari konversi gas rumah kaca dengan model karakterisasi yang berasal dari IPCC. Gas rumah kaca yang diperhitungkan merupakan 6 jenis gas rumah kaca yang ada dalam lampiran Protocol Kyoto. Gas rumah kaca dan potensi pemanasan global untuk model karakterisasi pada studi dapat dilihat pada Tabel 4.

Tabel 4 Potensi pemanasan global oleh GRK

\begin{tabular}{lr}
\hline \multicolumn{1}{c}{ Gas Rumah Kaca } & $\begin{array}{r}\text { Potensi Pemanasan Global } \\
\left(\mathrm{CO}_{2} \text {-eq }\right)^{1}\end{array}$ \\
\hline Karbon dioksida $\left(\mathrm{CO}_{2}\right)$ & 1 \\
Metana $\left(\mathrm{CH}_{4}\right)$ & 25 \\
Dinitrogen oksida $\left(\mathrm{N}_{2} \mathrm{O}\right)$ & 298 \\
Hidroflorokarbon $(\mathrm{HFC})$ & $12-14800$ \\
Perflorokarbon (PFC) & $7390-12200$ \\
Sulfur heksaklorida $\left(\mathrm{SF}_{6}\right)$ & 22800 \\
\hline
\end{tabular}

${ }^{1}$ IPCC (2012)

\subsection{Interpretasi Hasil (Life Cycle Interpretation)}

Tahap interpretasi hasil terdiri dari dua langkah penting, yaitu identifikasi isu penting dan evaluasi. Pada tahap identifikasi isu penting, interpretasi hasil dilakukan untuk melihat konsistensi dalam inventarisasi input output dan penilaian dampak lingkungan yang telah dilakukan dengan goal and scope yang telah ditentukan. Pada tahap evaluasi dapat dilakukan dengan pemeriksaan kelengkapan, sensitivitas dan konsistensi. Pemeriksaan kelengkapan dilakukan untuk memastikan seluruh informasi relevan dan diperlukan untuk interpretasi. Pemeriksaan sensitivitas dilakukan untuk menilai pengaruh hasil dan kesimpulan yang disebabkan oleh ketidakpastian data, metode atau perhitungan. Pemeriksaan konsistensi dilakukan untuk memeriksa asumsi dan data agar tetap konsisten dengan tujuan dan ruang lingkup.

\subsection{Perhitungan Penurunan Dampak Pemanasan Global}

Menurut ASI (2014), emisi $\mathrm{CO}_{2}$ yang berasal dari bahan bakar biomasa dianggap sebagai climate neutral atau tidak menghasilkan emisi $\mathrm{CO}_{2}$. Hasil perhitungan emisi $\mathrm{CO}_{2}$ yang berasal dari penggunaan biomasa (saw dust) akan menjadi pengurang dampak pemanasan global yang telah diperoleh dari hasil LCA. Untuk mengetahui penurnan dampak pemanasan global karena climate neutral perlu diketahui faktor emisi dari biomasa (saw dust) yang digunakan.

Untuk mengetahui faktor emisi bahan biomasa akan dilakukan perhitungan menggunakan persamaan linear berdasarkan penggunaan bahan bakar dengan pada kedua kasus yang diamati. Hasil emisi faktor yang diperoleh akan menjadi input bagi model perhitungan penurunan d untuk mengetahui penurunan dampak pemanasan global di plant tahun 2013-2020. Proses perhitungan akan menggunakan pendekatan sistem yang dibantu dengan pembuatan causal loop memudahkan proses perhitungan.

\section{Hasil dan Pembahasan}

\subsection{Tujuan dan Batasan LCA}

Studi LCA ini dilakukan untuk mengetahui perubahan dampak pemanasan global yang terjadi karena penggunaan $\mathrm{AF}$ (saw dust) pada aktivitas coprocessing. Untuk mengetahui perubahan dampak pemanasan global maka perlu dihitung penggunaan energi. Hal ini dikarenakan pada penggunaan energi tersebut dapat mempengaruhi besaran pemanasan global yang dihasilkan. Penggunaan energi yang diamati meliputi energi panas, listrik dan solar.

Penentuan batasan sistem produksi semen dilakukan melalui pendekatan cradle to gate yaitu, dari proses penambangan hingga proses pengantongan semen ditambah dengan sistem penyediaan AF yang ditujukan sebagai subtitusi batubara pada pembakaran di unit 
proses kiln untuk memproduksi klinker. Pembatasan pengamatan dimulai dari ekstraksi material yang berasal dari alam yang digunakan sebagai bahan baku pembuatan semen dan bahan bakar dalam penyediaan energi hingga proses pengantongan semen yang telah siap untuk dipasarkan. Tahap penyediaan energi akan dibagi menjadi dua kasus yaitu, melalui penggunaan $100 \%$ batubara dan batubara yang telah disubtitusi bahan bakar alternatif (AF). Berdasarkan Gambar 1 yang merupakan batasan dalam studi LCA terdapat 5 unit proses pada proses produksi semen dan 2 unit proses pada penyediaan bahan bakar. Unit proses pada proses produksi semen yaitu penambangan material (mining), raw mill, kiln, penggilingan akhir (cement mill), dan pengantongan sedangkan unit proses pada proses penyediaan bahan bakar adalah penyediaan batubara (BB) dan penyediaan AF pada alternative fuel and raw material (AFR). Pengamatan penyediaan batubara dimulai dari tahap penambangan hingga pengolahan batubara (coal mill) di dalam plant sedangkan pada pengamatan penyediaan $\mathrm{AF}$ (saw dust) dimulai dari industri hingga pengolahan di plant. AF yang digunakan untuk mensubtitusi batubara merupakan limbah yang dihasilkan oleh perusahaan sehingga proses penyediaan AF relatif lebih sederhana dibandingan dengan penyediaan batubara. Proses penggunaan energi yang berbeda merupakan kasus yang akan dibandingkan. Kasus ini berdasarkan proses produksi yang dilaksanakan di plant.

Studi ini hanya fokus pada emisi gas rumah kaca yang menyebabkan dampak pemanasan global karena penggunaan bahan bakar alternatif di plant. Hal ini sesuai dengan tujuan yang telah ditetapkan sebelumnya. Hasil dari analisis LCA akan digunakan untuk perhitungan pengurangan emisi dampak pemanasan global yang terjadi di plant.

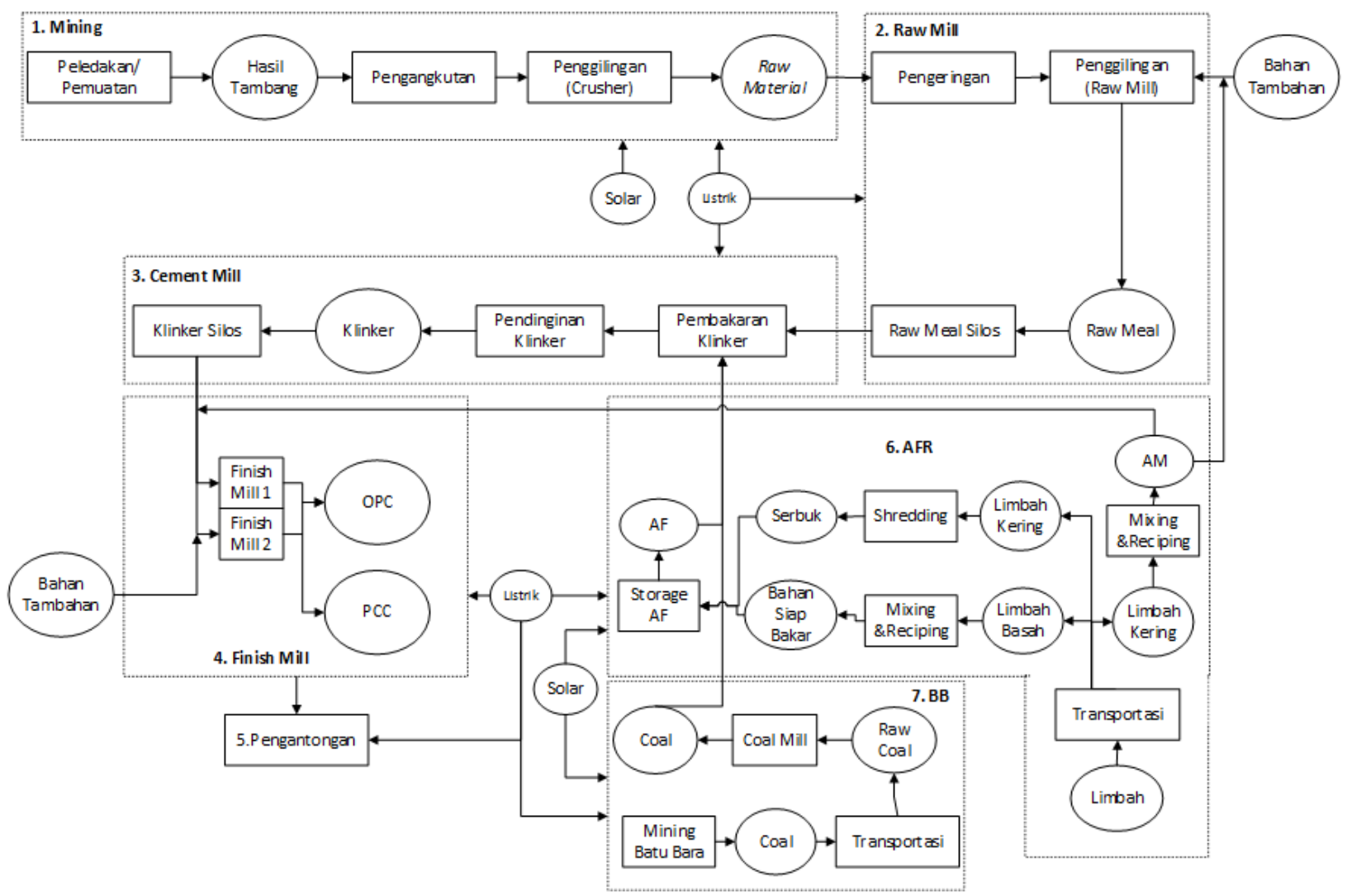

Gambar 1. Lingkup proses produksi semen

Tabel 5. Kasus penggunaan bahan bakar

\begin{tabular}{|c|c|c|c|c|c|c|c|c|}
\hline \multirow[b]{2}{*}{ Kasus } & \multicolumn{2}{|c|}{ Fuel (Ton) } & \multirow{2}{*}{$\begin{array}{c}\text { Komposisi } \\
\text { AF }\end{array}$} & \multicolumn{2}{|c|}{ Komposisi Fuel (\%) } & \multicolumn{2}{|c|}{ Kapasitas Pemanasan (GJ) } & \multirow{2}{*}{$\begin{array}{l}\text { Produksi semen } \\
\text { (ton) }\end{array}$} \\
\hline & Coal & $\mathrm{AF}$ & & Coal & $\mathrm{AF}$ & Coal & $\mathrm{AF}$ & \\
\hline 1 & 24.00 & 0.00 & - & 100.00 & 0.00 & 595.73 & 0.00 & 242.91 \\
\hline 2 & 21.40 & 15.08 & Saw Dust & 58.66 & 41.34 & 521.42 & 214.24 & 170.29 \\
\hline
\end{tabular}

\subsection{Studi Kasus Penggunaan Bahan bakar}

Kasus penggunaan bahan bakar dibagi menjadi dua, yaitu kasus yang menggunakan batubara $100 \%$ sebagai bahan bakar dan kasus penggunaan batubara yang telah disubtitusi AF (saw dust). Subtitusi AF yang dilakukan menggunakan saw dust (serbuk gergaji) dengan tingkat subtitusi sebesar $41.34 \%$. Kedua kasus tersebut akan diamati untuk dibandingkan sesuai dengan goal pada studi LCA yang telah dibuat. Data kasus pada Tabel 5 
yang diamati merupakan data dari proses produksi semen yang telah dilakukan di plant.

Berdasarkan data yang diperoleh, panas yang dihasilkan per ton batubara lebih besar dibandingkan panas yang dihasilkan per ton AF dengan perbandingan panas yang dihasilkan oleh 0.58 ton-batubara setara dengan panas yang dihasilkan 1 ton AF. Pada Tabel 5 dapat dilihat perbedaan jumlah penggunaan bahan bakar pada kedua kasus. Kuantitas bahan bakar yang digunakan pada kasus 2 jauh lebih banyak dibandingkan kasus 1 sehingga menghasilkan energi panas yang lebih besar dengan nilai 735.66 GJ pada kasus 2 dan 595.73 GJ pada kasus 1. Hal ini dikarenakan kasus 2 menghasilkan semen lebih besar dengan total produksi 242.91 ton-semen dan kasus 1 menghasilkan 170.29 ton-semen. Produksi semen yang dihasilkan di plant terdiri dari dua jenis produk, yaitu ordinary portland cement (OPC) dan portland composite cement (PCC). Semen Kedua jenis produk semen tersebut merupakan jenis semen yan dihasilkan di plant, namun yang dilihat pada studi ini hanya semen secara umum. Semen yang dihasilkan berbanding lurus dengan jumlah klinker yang dihasilkna pada rposes pembakaran di kiln. Rasio kandungan klinker menjadi semen pada kasus 1 dan 2 adalah $89.73 \%$ dan $85.05 \%$. Perbedaan kandungan klinker terjadi tergantung pada bahan atau material tambahan yang digunakan pada penggilingan akhir di cement mill. Penggunaan material tambahan dilakukan sesuai dengan kebutuhan perusahaan dalam memproduksi jenis semen yang dibutuhkan untuk memenuhi permintaan konsumen. Perbedaan jumlah produksi semen pada masing-masing kasus menjadi alasan pentingnya penggunaan functional unit sebesar 1 ton-semen sehingga kedua kasus dapat dibandingkan.

\subsection{Kebutuhan Energi pada Produksi Semen}

Kebutuhan energi pada produksi semen semen diketahui dari tabel inventori yang telah disusun berdasarkan dengan tujuan dan ruang lingkup yang telah ditentukan. Berdasarkan ruang lingkup yang telah dibuat sebelumnya, penggunaan energi pada unit proses mining hingga pengantongan tidak ada perlakuan sistem yang berbeda pada kedua kasus.
Perlakuan sistem yang berbeda hanya terdapat pada unit proses AFR dan BB sesuai dengan penggunaan bahan bakar yang dilakukan.

Pada Tabel 6 dapat dilihat penggunaan energi panas, energi listrik dan solar pada kasus 1 dan 2. Penggunaan energi panas hanya dibutuhkan untuk pembakaran di kiln untuk menghasilkan klinker yang merupakan bahan baku utama dalam pembuatan semen. Energi panas yang digunakan di kiln dihasilkan dari bahan bakar yang berasal dari batubara dan AF. Untuk memproduksi semen membutuhkan energi panas sebesar 3.50 GJ/ton-semen pada kasus 1 dan 3.03 GJ/ton-semen pada kasus 2. Pada penilaian penggunaan energi panas pada produksi semen penggunaan panas per-ton-klinker sering dijadikan patokan dalam kebutuhan panas pada industri semen dibandingkan penggunaan panas pada produksi per ton semen. Hal ini dikarenakan energi panas hanya dibutuhkan pada unit proses kiln untuk produksi klinker. Nilai penggunaan panas pada produksi per ton klinker lebih mewakili nilai sebenarnya penggunaan panas di industri semen dibandingkan penggunaan panas pada produksi per ton semen karena adanya faktor material tambahan yang berbeda-beda sesuai jenis semen yang diproduksi pada penggilingan semen. Kebutuhan energi panas pada pembuatan klinker di kasus 1 dan 2 memiliki nilai sebesar $3.90 \mathrm{GJ} /$ tonklinker dan $3.37 \mathrm{GJ} /$ ton-klinker. Nilai tersebut dapat dibandingkan dengan rataan yang didapatkan KLH (2014) sebesar 3.64 GJ/ton-klinker. Nilai energi panas pada produksi per ton klinker lebih tinggi dibandingkan dengan kebutuhan energi panas yang dibutuhkan pada produksi per ton semen. Hal ini dikarenakan jumlah semen yang dihasilkan lebih banyak dibandingkan jumlah klinker karena faktor material tambahan di penggilingan semen pada unit proses cement mill..

Pada penggunaan energi listrik, unit proses raw mill merupakan pengguna energi listrik tertinggi diikuti dengan unit proses cement mill pada kedua kasus. Hal ini menandakan bahwa proses penggilingan material pada produksi semen memerlukan energi listrik yang tinggi. Pada seknario 1 dan 2 pernggunaan listrik perton-semen sebesar $126.43 \mathrm{kWh} /$ ton-semen dan 117.92 $\mathrm{kWh} /$ ton-semen. Nilai penggunaan listrik yang diperoleh dari nilai rataan dunia sebesar $111 \mathrm{kWh} /$ tonsemen (WBCSD dan IEA, 2009).

Tabel 6. Penggunaan energi panas, listrik dan solar pada kasus 1 dan 2

\begin{tabular}{|c|c|c|c|c|c|c|c|}
\hline \multirow{2}{*}{ No. } & \multirow{2}{*}{ Unit Proses } & \multicolumn{2}{|c|}{ Energi Panas (GJ/ton) } & \multicolumn{2}{|c|}{ Energi Listrik (kWh/ton) } & \multicolumn{2}{|c|}{ Solar (L/ton) } \\
\hline & & Kasus 1 & Kasus 2 & Kasus 1 & Kasus 2 & Kasus 1 & Kasus 2 \\
\hline 1 & Mining & 0 & 0 & 1.79 & 1.36 & 0.09 & 0.07 \\
\hline 2 & Raw Mill & 0 & 0 & 51.70 & 38.97 & 0.00 & 0.00 \\
\hline 3 & Kiln & 3.50 & 3.03 & 24.86 & 23.13 & 0.00 & 0.00 \\
\hline 4 & Cement Mill & 0 & 0 & 41.29 & 45.67 & 0.00 & 0.00 \\
\hline 5 & Pengantongan & 0 & 0 & 1.60 & 2.70 & 0.00 & 0.00 \\
\hline 6 & AFR & 0 & 0 & 0.00 & 2.06 & 0.00 & 0.06 \\
\hline \multirow[t]{2}{*}{7} & $\mathrm{BB}$ & 0 & 0 & 5.19 & 4.03 & 2.10 & 1.31 \\
\hline & Total & 3.50 & 3.03 & 126.43 & 117.92 & 2.19 & 1.44 \\
\hline
\end{tabular}

Perbedaan nilai pada penggunaan energi panas dan listrik yang terjadi antara kasus 1 dan 2 dikarenakan adanya fluktuasi penggunaan energi dalam produksi semen. Hal ini dikarenakan unit proses AFR dan BB tidak menggunakan energi panas sedangkan pada penggunaan energi listrik unit proses AFR dan BB tidak berpengaruh terlalu besar pada penggunaan energi listrik keseluruhan. Fluktuasi nilai yang ada 
dikarenakan adanya pengaruh dari keadaan di pabrik pada proses produksi. Nilai penggunaan listrik pada setiap unit proses untuk menghasilkan produk semen di plant selalu bervariasi karena sistem tenaga listrik di industri semen tidak pernah beroperasi pada tegangan dan frekuensi yang konstan (Armansyah et al., 2012). Hal tersebut dapat mempengaruhi nilai penggunaan listrik pada produksi semen yang memerlukan energi listrik yang tinggi. Pada penggunaan energi panas pada produksi tiap ton klinker nilai yang diperlukan berbedabeda dikarenakan adanya fluktuasi penggunaan energi panas yang ada di kiln. Salah satu faktor yang mempengaruhi fluktuasi penggunaan panas yang ada adalah nilai kecepatan masukan material dan bahan bakar untuk proses pembakaran yang berbeda-beda di kiln. Nilai yang berbeda-beda tersebut disesuaikan dengan kapasitas dan kualitas mesin yang ada di plant agar kualitas mesin dapat terus terjaga dengan tidak menurunkan kualitas dan kuantitas pembakaran dalam produksi klinker (Wahyu dan Sumiati, 2009).

Pada penggunaan solar, nilai tertinggi terdapat pada unit proses BB (batubara). Hal ini dikarenakan tambang batubara yang berada jauh dari plant dibandingkan unit proses AFR (penyediaan AF). Nilai kebutuhan solar dalam penyediaan AF lebih rendah dibandingkan batubara karena sumber AF yang masih berada di pulau yang sama dibandingkan dengan batu bara yang berada di luar pulau. Pada kasus 1 kebutuhan solar yang diperlukan lebih tinggi karena seluruh kebutuhan energinya didapat dari penggunaan batubara dibandingkan dengan kasus 2 yang telah disubtitusi AF (biomasa).

\subsection{Kebutuhan Energi Total}

Untuk memudahkan analisis seluruh kebutuhan energi seperti energi panas, listrik dan solar akan dijumlahkan untuk dihitung secara keseluruhan dalam satu satuan. Seluruh komponen energi tersebut akan disamakan satuannya menjadi Mega joule (MJ) sebagai satuan energi total. Menurut KLH (2012), satu L-solar di Indonesia memiliki energi panas sebesar 38 MJ. Pada Tabel 7 dapat dilihat nilai konversi energi menjadi MJ yang berasal dari hasil inventori Tabel 6. Pada Tabel 7 dapat diketahui bahwa penggunaan energi terbesar pada kedua kasus tersebut terdapat pada penggunaan energi di unit proses kiln dengan kontribusi penggunaan energi diatas $88 \%$. Penggunaan energi tertinggi di kiln adalah energi panas. Hal ini menandakan penggunaan energi panas merupakan pernggunaan energi terbesar dalam produksi semen. Secara umum pola penggunaan energi pada kedua kasus memiliki kesamaan kecuali pada unit proses AFR. Pada kasus 1 memiliki unit proses AFR yang tidak menggunakan energi sama sekali karena pada pada kasus 1 tidak menggunakan AF, berbeda dengan kasus 2 yang disubtitusi AF. Perbedaan nilai pada kedua kasus dikarenakan adanya perbedaan nilai pada penggunaan energi panas di kiln. Perbedaan penggunaan energi di kiln dapat berdampak signifikan pada penggunaan energi semen secara keseluruhan karena besarnya energi yang digunakan pada unit proses tersebut.

\subsection{Dampak Pemanasan Global}

Berdasarkan tabel inventori dapat diketahui dampak pemanasan global dari proses produksi semen yang dilakukan melalui model karakterisasi yang telah ditentukan sebelumnya. Berdasarkan tujuan dan ruang lingkup yang ditentukan di awal, studi ini hanya fokus pada dampak pemanasan global. Pada Tabel 9 dapat dilihat bahwa unit proses kiln pada kasus sebelum asumsi climate neutral $(\mathrm{CN})$ diberlakukan merupakan penyumbang dampak pemanasan global tertinggi pada kedua kasus dengan presentase sebesar $89.01 \%$ untuk kasus 1 dan $91.05 \%$ untuk kasus 2. Nilai emisi sebesar itu terjadi karena adanya pembakaran yang terjadi di kiln. Proses pembakaran bahan bakar dan kalsinasi batukapur merupakan proses utama yang menyumbang emisi gas rumah kaca pada produksi semen (KLH, 2014).

Tabel 7. Kebutuhan energi total untuk produksi semen

\begin{tabular}{|c|c|c|c|c|c|}
\hline \multirow{2}{*}{ No. } & \multirow{2}{*}{ Unit Proses } & \multicolumn{2}{|c|}{ Kasus 1} & \multicolumn{2}{|c|}{ Kasus 2} \\
\hline & & MJ/ton & $\%$ & $\mathrm{MJ} /$ ton & $\%$ \\
\hline 1 & Mining & 9.89 & 0.25 & 7.51 & 0.21 \\
\hline 2 & Raw Mill & 186.12 & 4.61 & 140.29 & 4.00 \\
\hline 3 & Kiln & 3587.81 & 88.88 & 3111.83 & 88.71 \\
\hline 4 & Cement Mill & 148.66 & 3.68 & 164.41 & 4.69 \\
\hline 5 & Pengantongan & 5.76 & 0.14 & 9.72 & 0.28 \\
\hline 6 & AFR & 0.00 & 0.00 & 9.75 & 0.28 \\
\hline \multirow[t]{2}{*}{7} & $\mathrm{BB}$ & 98.32 & 2.44 & 64.29 & 1.83 \\
\hline & Total & 4036.55 & 100 & 3507.81 & 100 \\
\hline
\end{tabular}

Pada Tabel 9 dapat diketahui bahwa kasus 1 yang tidak disubtitusi AF memiliki nilai dampak pemanasan global yang lebih rendah dibanding kasus 2 yang telah disubtitusi AF dengan nilai sebesar 0.84 ton $\mathrm{CO}_{2}$-eq per ton semen pada kasus 1 dan 0.92 ton- $\mathrm{CO}_{2}$-eq/tonsemen pada kasus 2 . Hal ini menandakan penggunaan AF tidak menurunkan emisi gas rumah kaca pada proses pembakaran secara langsung pada produksi semen berdasarkan data inventori unit proses kiln yang merupakan data pengukuran emisi langsung. Hal ini dikarenakan penggunaan AF (saw dust) turut menyumbang emisi $\mathrm{CO}_{2}$ pada saat pembakaran. Selain itu, pada pembakaran saw dust memerlukan kuantitas bahan bakar yang lebih banyak dibandingkan batubara untuk menghasilkan panas yang sama dengan batubara sehingga membuat jumlah emisi $\mathrm{CO}_{2}$ yang dihasilkan dari pembakaran kasus 2 lebih tinggi dibandingkan dengan kasus 1 yang berpengaruh pada dampak 
pemanasan global yang dihasilkan oleh setiap ton semen pada masing-masing kasus. Untuk unit proses AFR dan BB yang merupakan pembeda dari kedua kasus yang dibandingkan tidak memiliki dampak pemanasan global yang signifikan pada produksi semen sehingga tidak terlalu terlihat pengaruhnya. Menurut Kajaste dan Hurme (2016), rataan nilai emisi gas ruamh kaca per ton semen dunia sebesar 0.77 ton $\mathrm{CO}_{2}$-eq per ton-semen dengan rentang nilai antara 0.65-0.92 ton $\mathrm{CO}_{2}$-eq per ton-semen. Hal ini menandakan hasil dari studi LCA yang dilakukan pada Tabel 9 masih berada di rentang nilai negara-negara yang ada di dunia.

Walaupun memiliki pembatasan yang sama (cradle to gate) dalam perhitungan yang dilakukan oleh Kajaste dan Hurme (2016), namun perbedaan asumsi, data serta metode yang digunakan pada perhitungan dampak pemanasan global dapat berbeda sehingga perbedaan hasil dimungkinkan dapat terjadi. Perbedaan dalam penentuan batasan sistem dapat membuat perbedaan dalam komponen-komponen yang diperhitungkan pada penentuan dampak ( $\mathrm{Li}$ et al., 2014). Selain itu, nilai dampak pemanasan global yang berbeda dapat disebabkan adanya perbedaan teknologi yang digunakan negara lain.

\subsection{Asumsi Climate Neutral (CN)}

Berdasarkan data dampak pemanasan global, nilai dampak pemanasan global pada kasus 1 lebih rendah dibandingkan dengan kasus 2. Penurunan emisi karena penggunaan AF khususnya biomasa dapat terjadi karena adanya asumsi climate neutral $(\mathrm{CN})$. Menurut petunjuk teknis perhitungan dan pelaporan emisi $\mathrm{CO}_{2}$ industri semen yang dikeluarkan Kementrian Perindustrian, emisi $\mathrm{CO}_{2}$ yang berasal dari bahan bakar biomassa dianggap sebagai climate neutral atau tidak menghasilkan emisi $\mathrm{CO}_{2}$ (ASI, 2014) Alasan dibalik asumsi climate neutral tersebut adalah karena karbon yang tersimpan di dalam tanaman selama pertumbuhan akan dilepaskan kembali dalam jumlah dan bentuk yang sama dengan cara terdekomposisi secara natural ataupun dibakar sehingga hal tersebut tidak menambah gas rumah kaca yang ada di atmosfer (Wiloso et al., 2016).

Asumsi climate neutral merupakan kebijakan yang diakui oleh Kementrian Perindustrian dalam petunjuk teknis perhitungan dan pelaporan emisi $\mathrm{CO}_{2}$ industri semen. Asumsi climate neutral dapat membuat perbedaan hasil pada perhitungan dampak pemanasan global di Industri semen yang akan membuat perbedaan perhitungan dengan hasil pengukuran yang sebenarnya. Sesuai dengan hasil inventori, pembakaran AF khususnya biomasa berkontribusi pada emisi gas rumah kaca yang dihasilkan, namun dengan asumsi climate neutral nilai tersebut menjadi hilang atau tidak diperhitungkan. Bahan bakar biomasa tidak selalu dapat diasumsikan sebagai climate neutral, bahkan terdapat kasus dimana penggunaan biomasa menghasilkan emisi karbon yang lebih banyak dari bahan bakar fosil (Johnson, 2009). Hal ini membuat asumsi climate neutral masih menjadi perdebatan secara akademik terutama pada cara penggunaan asumsi tersebut. Pada asumsi climate neutral, penilaian secara ekonomi menjadi salah satu kunci dalam implementasi asumsi yang dilakukan (Goodfield et al., 2014).

Untuk mengetahui pengaruh $\mathrm{CN}$ pada penurunan dampak pemanasan global maka perlu diketahui faktor emisi dari biomasa yang digunakan. Untuk mengetahui fakor emisi biomasa maka perlu diketahui faktor emisi batubara karena kedua bahan bakar tersebut terbakar bersama. Perhitungan faktor emisi batubara dan biomasa dihitung menggunakan persamaan linear yang dapat dilihat pada persamaan yang ada di bawah. Menurut data dari KLH (2014), emisi $\mathrm{CO}_{2}$ pada kiln yang berasal dari proses pembakaran bahan bakar fosil menyumbang sebesar $33.26 \%$ dari total nilai emisi di kiln. Selain pembakaran fosil, kalsinasi $(61.61 \%)$ dan penggunaan listrik $(5.13 \%)$ turut menyumbang emisi $\mathrm{CO}_{2}$ di kiln. Faktor emisi batubara dihasilkan dari persamaan penggunaan batubara pada kasus 1 terhadap emisi $\mathrm{CO}_{2}$ yang dihasilkan dari pembakaran batubara (1) sehingga emisi faktor batubara dapat diketahui (2). Nilai faktor emisi batubara (2) yang telah diperoleh dimasukan ke persamaan penggunaan batubara dan biomasa terhadap emisi $\mathrm{CO}_{2}$ yang dihasilkan dari penggunaan bahan bakar sesuai dengan kasus 2 (3). Berdasarkan persamaan (3) akan diketahui faktor emisi biomasa (4). Berdasarkan hasil perhitungan dapat dikaetahui bahwa faktor emisi biomasa lebih tinggi dibandingkan dengan batubara. Nilai faktor emisi batubara dan biomasa yang didapatkan pada penelitian ini tidak jauh berbeda dengan nilai pembanding yang berasal dari data CDM (2012) dan ASI (2014).

Tabel 8. Faktor emisi bahan bakar

\begin{tabular}{|c|c|c|c|c|c|c|}
\hline \multirow{2}{*}{ Kasus } & \multicolumn{2}{|c|}{ Fuel (ton) } & \multirow{2}{*}{$\begin{array}{l}\text { Emisi Bahan Bakar } \\
\quad\left(\text { ton- } \mathrm{CO}_{2} \text { ) }\right.\end{array}$} & \multirow{2}{*}{ Bahan Bakar } & \multirow{2}{*}{$\begin{array}{c}\text { Faktor Emisi } \\
\text { (ton- } \mathrm{CO}_{2} / \text { ton Bahan bakar) }\end{array}$} & \multirow{2}{*}{$\begin{array}{c}\text { Pembanding } \\
\text { (ton- } \mathrm{CO}_{2} / \text { ton Bahan bakar) }\end{array}$} \\
\hline & Coal & $\mathrm{AF}$ & & & & \\
\hline 1 & 24 & 0.00 & 43.42 & Batubara & $1.81^{1}$ & $1.89^{3}$ \\
\hline 2 & 21.4 & 15.08 & 69.88 & Biomasa & $2.07^{2}$ & $1.86^{4}$ \\
\hline
\end{tabular}

${ }^{1}$ Hasil perhitungan dari persamaan kasus 1 (2)

${ }^{2}$ Hasil perhitungan dari persamaan kasus 2 (3)

${ }^{3}$ Diolah dari CDM (2012)

${ }^{4}$ Diolah dari ASI (2014) 


$$
a=1.81
$$

$21.4 a+15.08 b=69.88$

$$
b=2.07
$$

$\mathrm{a}=$ faktor emisi batubara

$\mathrm{b}=$ faktor emisi biomasa

Faktor emisi dari biomasa selanjutnya akan dikalikan dengan jumlah biomasa yang digunakan pada proses pembakaran untuk produksi semen yang akan menjadi faktor pengurang emisi $\mathrm{CO}_{2}$ bagi kasus 2 karena asumsi CN. Pengurangan tersebut akan menjadi faktor penurunan emisi yang terjadi pada penggunaan biomasa sebagai AF. Pada Tabel 9 dapat dilihat hasil penurunan dampak pemanasan global karena asumsi CN. Dampak pemanasan global kasus 2 sebelum asumsi $\mathrm{CN}$ sebesar 0.92 ton- $\mathrm{CO}_{2}$-eq/ton-semen turun menjadi 0.79 ton- $\mathrm{CO}_{2}$-eq/ton-emen. Penurunan yang terjadi sebesar $14.65 \%$ sedangkan pada kasus 1 tidak terjadi penurunan karena tidak menggunakan subtitusi bahan bakar alternatif biomasa. Penurunan emisi terjadi di unit proses kiln yang menjadi tempat penggunaan biomasa untuk proses pembakaran. Penurunan dampak pemanasan global yang terjadi membuat dampak pemanasan global kasus 2 menjadi lebih rendah dibandingkan kasus 1. Hal ini membuktikan bahwa asumsi $\mathrm{CN}$ dapat menurunkan dampak pemanasan global di industri semen.

\subsection{Perhitungan Penurunan Dampak Pemanasan Global}

Perhitungan penurunan dampak pemanasan global di plant dilakukan berdasarkan berdasarkan asumsi biomasa sebagai climate neutral $(\mathrm{CN})$. Tujuan dari model yang dibuat adalah untuk mengetahui penurunan emisi gas rumah kaca karena penggunaan $\mathrm{AF}$ khususnya biomasa. Grafik causal loop untuk perhitungan penurunan dampak pemanasan global dapat dilihat di Gambar 3. Produksi semen yang dilakukan akan mempengaruhi kebutuhan energi khususnya energi panas untuk yang ada di plant. Pemenuhan energi panas disediakan melalui bahan bakar yang terdiri dari batubara dan AF. AF yang digunakan dapat dibagi menjadi dua, yaitu yang berasal dari biomasa dan non biomasa. Dengan asumsi climate neutral, penggunaan biomasa dianggap tidak menyumbang emisi $\mathrm{CO}_{2}$ yang dapat menjadi pengurang bagi emisi yang sebenarnya dihasilkan dari produksi semen.

Perhitungan yang dilakukan berdasarkan dengan penggunaan biomasa dari tahun 2013-2016 yang telah dilakukan di plant sedangkan untuk penggunaan biomasa dari 2017-2020 merupakan prediksi mengikuti target yang telah direncanakan di plant. Pada tahun 2020 ditargetkan plant dapat menggunakan AF sebesar $20 \%$ dalam setahun penuh. Untuk produksi semen dari tahun 2017-2020 diprediksikan akan stabil karena tidak ada rencana penambahan kapasitas produksi plant dari perusahaan. Hal ini dikarenakan proses penambahan kapasitas semen di Indonesia mengalami stagnansi mulai tahun 2017 hingga tahun 2020 karena kapasitas produksi semen jauh lebih tinggi dibandingkan permintaan semen yang ada di pasaran (Santoso, 2015). Tidak adanya penambahan kapasitas produksi semen akan mengakibatkan tidak adanya penambahan penggunaan bahan bakar yang ada di plant.

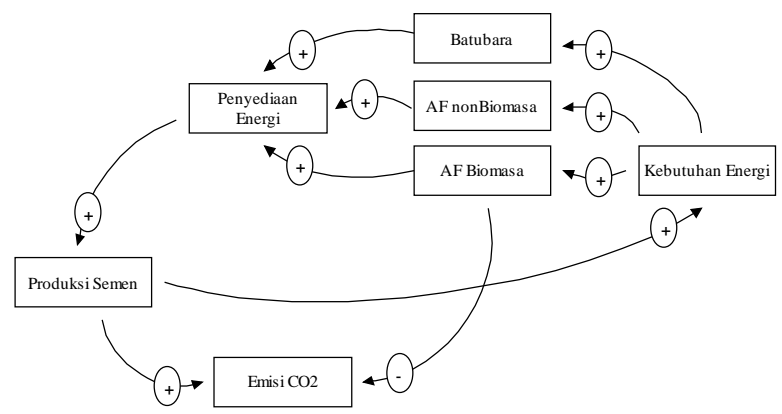

Gambar 2. Causal Loop penurunan dampak pemansan global dengan asumsi climate neutral (CN)

\begin{tabular}{|c|c|c|c|c|c|c|c|c|c|}
\hline \multirow{3}{*}{ No. } & \multirow{3}{*}{ Unit Proses } & \multicolumn{4}{|c|}{ Sebelum CN } & \multicolumn{4}{|c|}{ Setelah CN } \\
\hline & & \multicolumn{2}{|r|}{ Kasus 1} & \multicolumn{2}{|r|}{ Kasus 2} & \multicolumn{2}{|c|}{ Kasus 1} & \multicolumn{2}{|r|}{ Kasus 2} \\
\hline & & $(\%)$ & ton- $\mathrm{CO}_{2}$-eq/ton & $(\%)$ & ton- $\mathrm{CO}_{2}-\mathrm{eq} /$ ton & $(\%)$ & ton- $\mathrm{CO}_{2}-\mathrm{eq} /$ ton & $(\%)$ & ton- $\mathrm{CO}_{2}$-eq/ton \\
\hline 1 & Mining & 0.21 & 0.0018 & 0.14 & 0.0013 & 0.21 & 0.0018 & 0.17 & 0.0013 \\
\hline 2 & Raw Mill & 5.17 & 0.0434 & 3.55 & 0.0327 & 5.17 & 0.0434 & 4.16 & 0.0327 \\
\hline 3 & Kiln & 89.01 & 0.7481 & 91.05 & 0.8400 & 89.01 & 0.7481 & 90.48 & 0.7115 \\
\hline 4 & Cement Mill & 4.13 & 0.0347 & 4.16 & 0.0384 & 4.13 & 0.0347 & 4.88 & 0.0384 \\
\hline 5 & Pengantongan & 0.16 & 0.0013 & 0.25 & 0.0023 & 0.16 & 0.0013 & 0.29 & 0.0023 \\
\hline 6 & AFR & 0.00 & 0.0000 & 0.02 & 0.0002 & 0.00 & 0.0000 & 0.02 & 0.0002 \\
\hline \multirow[t]{2}{*}{7} & $\mathrm{BB}$ & 1.33 & 0.0112 & 0.83 & 0.0077 & 1.33 & 0.0112 & 0.97 & 0.0077 \\
\hline & Total & 100.00 & 0.8405 & 100.00 & 0.9226 & 100.00 & 0.8405 & 100.00 & 0.7864 \\
\hline
\end{tabular}

Tabel 9. Dampak pemanasan global setiap unit proses

Berdasarkan perhitungan yang dilakukan penurunan $\mathrm{CO}_{2}$-eq dengan asumsi climate neutral dari penggunaan biomasa dapat menurunkan dampak pemanasan global rata-rata sebesar $71,601.46$ ton- $\mathrm{CO}_{2-}$ eq/tahunnya dengan rincian penurunan emisi tahun 2013-2015 sebesar 71,827.64 ton- $\mathrm{CO}_{2}$-eq per tahun dan tahun 2016-2020 sebesar 71,465.76 ton- $\mathrm{CO}_{2}$-eq/tahun.
Data penurunan emisi dengan asumsi tersebut dapat terjadi bila plant dengan terus meningkatkan penggunaan AF hingga 20\% di tahun 2020 dengan peningkatan secara bertahap dari tahun 2017-2020 dengan asumsi produksi semen tetap stabil seperti tahun-tahun sebelumnya. Berdasarkan data dari Tabel 10, dapat dilihat bahwa adanya penurunan nilai 
pengurangan dampak pemanasan global dari tahun 2013 hingga tahun 2016 yang disebabkan terjadinya penurunan permintaan semen pada tahun-tahun tersebut karena persaingan yang mengetat di industri semen. Hal tersebut mengakibatkan penurunan pada produksi semen yang terjadi di perusahaan secara keseluruhan sehingga mempengaruhi penggunaan bahan bakar di plant. Penyesuaian produksi semen yang terjadi berakibat pada pengurangan penggunaan AF khususnya biomasa yang terjadi di plant. Pada tahun 2017-2020 pengurangan emisi kembali meningkat dikarenakan perusahaan berkomitmen untuk meningkatkan kembali penggunaan AF hingga 20\% seiring dengan membaik permintaan semen yang ada di pasaran. Hasil perhitungan ini dapat digunakan sebagai masukan dalam perhitungan penurunan emisi spesifik total perusahaan yang berasal dari seluruh plant yang dimiliki perusahaan dalam rangka memenuhi peraturan pemerintah untuk penurunan emisi. Hal ini dikarenakan pada Permenperin No. 12 Tahun 2012 menyatakan perhitungan penurunan dampak pemanasan global harus dilakukan selama satu tahun dan penurunan dinyatakan secara total setiap tahunnya sedangkan pada perhitungan penurunan dampak pemanasan gobal karena asumsi $\mathrm{CN}$ pada studi ini hanya menghitung pada kasus satu kali aliran produksi dan pada satu plant yang dimiliki perusahaan.

Tabel 10. Hasil perhitungan penurunan dampak pemanasan global

\begin{tabular}{ccc}
\hline Tahun & $\begin{array}{c}\text { Penggunaan } \\
\text { Biomasa (ton) }\end{array}$ & $\begin{array}{c}\text { Penurunan dampak } \\
\text { pemanasan global } \\
\text { (ton } \mathrm{CO}_{2} \text {-eq) }\end{array}$ \\
\hline 2013 & 51,027 & 105,470 \\
2014 & 29,961 & 61,928 \\
2015 & 23,263 & 48,084 \\
2016 & 14,134 & 29,215 \\
2017 & 26,770 & 55,333 \\
2018 & 35,381 & 73,130 \\
2019 & 43,991 & 90,926 \\
2020 & 52,601 & 108,723 \\
\hline
\end{tabular}

2017-2020 = prediksi penggunaan biomasa

Penurunan DPG (2) = Pengunaan biomasa (1) x FE Biomasa

$\mathrm{FE}$ Biomasa $=2.07$ ton $-\mathrm{CO}_{2} /$ ton biomasa

\section{Kesimpulan}

Berdasarkan hasil LCA, kasus 1 yang menggunakan batubara $100 \%$ membutuhkan energi panas sebesar $3.50 \mathrm{GJ} /$ ton-semen, energi listrik sebesar 126.43 $\mathrm{kWh}$ /ton-semen, solar sebanyak $2.19 \mathrm{~L} /$ ton-semen dan menghasilkan dampak pemanasan global sebesar 0.84 ton- $\mathrm{CO}_{2}$-eq/ton-semen sedangkan pada kasus 2 yang menggunakan batubara yang telah disubtitusi saw dust sebesar $41.34 \%$ membutuhkan energi panas 3.03 GJ/ton-semen, energi listrik sebesar $117.92 \mathrm{kWh} /$ tonsemen, solar sebanyak 1.44 L/ton-semen dan menghasilkan dampak pemanasan global sebesar 0.92 ton- $\mathrm{CO}_{2}$-eq/ton-semen. Perbedaan penggunaan energi panas dan listrik yang terjadi karena adanya fluktuasi penggunaan energi panas dan listrik yang terjadi pada saat produksi semen di plant sedangkan pada penggunaan solar perbedaan terjadi karena adanya perbedaan penggunaan solar pada penyediaan energi di unit proses AFR dan BB. Asumsi climate neutral karena penggunaan biomasa sebagai bahan bakar dapat menurunkan dampak pemanasan global kasus 2 sebesar $14.65 \%$ dan menurunkan dampak pemanasan global di plant sebesar 71,601.46 ton- $\mathrm{CO}_{2}$-eq per tahun dari tahun 2013-2020. Hasil perhitungan penurunan emisi dapat digunakan sebagai masukan dalam perhitungan emisi total perusahaan untuk memenuhi peraturan pemerintah.

\section{Daftar Pustaka}

[1] [ASI] Asosiasi Semen Indonesia, 2014. Petunjuk Teknis Perhitungan dan Pelaporan Emisi $\mathrm{CO}_{2}$ Industri Semen. Kementerian Industri, Jakarta.

[2] [CDM] Clean Development Mechanism, 2012. Indocement alternative fuels project, pp 48 [terhubung berkala].https://cdm.unfccc.int/filestorage/0/Y/0/0Y0MXUD 1XLRMSVPW89U6M8P1MF1WIY/PDD_Indocement\%20 Alternative\%20Fuel_2006-05-

11.pdf? $\mathrm{t}=\mathrm{aXd8b3JiYTVrfDB6YC2qz0Q8obwHHrsPgAJV}$

[20 Ferbruari 2017]

[3] [ESDM] Kementrian Energi dan Sumberdaya Mineral, 2016. Faktor Emisi Gas Rumah Kaca Sistem Interkoneksi 2014. Dirjen Ketenagalistrikan, Jakarta.

[4] [IPCC] Intergovermental Panel of Climate Change, 2012 Climate change 2007, the physical science basis. IPCC, pp. 45. [terhubung berkala].https://www.ipcc.ch/pdf/assessmentreport/ar4/wg1/ar4-wg1-errata.pdf [8 Agustus 2017]

[5] [Kemenperin] Kementrian Peridustrian, 2012b. Peraturan Menteri Perindustrian Nomor 12 Tahun 2012 tentang Peta Panduan (Road Map) Pengurangan Emisi $\mathrm{CO}_{2}$ Industri Semen Indonesia. Kemenperin, Jakarta.

[6] [Kemenperin] Kementrian Perindustrian, 2012a. Draft Petunjuk Teknis Perhitungan Emisi Gas Rumah Kaca (GRK) di Sektor Industri. Badan Pengkajian Kebijakan Iklim dan Mutu Industri, Jakarta.

[7] [KLH] Kementrian Lingkungan Hidup, 2012. Pedoman Penyelenggaraan Inventarisasi Gas Rumah Kaca Nasional, Volume 1 Metodologi Perhitungan Tingkat Emisi Gas Rumah Kaca Pengadaan dan Penggunaan Energi. KLH, Jakarta.

[8] [KLH] Kementrian Lingkungan Hidup, 2014. Laporan Inventarisasi Gas Rumah Kaca Tahun 2014. KLH, Jakarta.

[9] [Setkab RI] Sekretariat Kabinet Republik Indonesia, 2011. Peraturan Presiden Nomor 61 Tahun 2011 tentang Rencana Aksi Nasional Penurunan Emisi Gas Rumah Kaca. Setkab RI, Jakarta.

[10] [WBCSD; IEA] World Busines Council for Sustainable Development, Internatioanl Energy Agency. 2009. Cement Technology Roadmap 2009, Carbon Emmisions Reduction Up to 2050. IEA Publications, Paris.

[11] Armansyah F., H. Hilal, Ifanda, A. Hasan, M. Iksan, E.S. Hariatie, B. Ismoyo, S. Syafei, A.P. Mayasari, K.P. Ola, A. Suhendra, 2012. Benchmark Kualitas Daya Industri Semen. BPPT Press, Jakarta.

[12] Baidya R., K.S. Ghosh, U.V. Parlikar, 2016. Co-processing of industrial waste in cement kiln - A robust system for material and energi recovery. Procedia Enviromental Sciences. 31, pp. 309-317.

[13] Finkbeiner M., A. Inaba, R.B.H. Tan, K. Christiansen, H.J. Kluppel, 2006. The New International Standards for Life Cycle Assesment: ISO 14040 and ISO 14044. Int J LCA. 11(2), pp. 80-86.

[14] Finkbeiner, M., 2016. Introducing Special Types of Life Cycle Assesment. Dalam Finkbeiner M, editor. LCA CompendiumThe Complete World of Life Cycle Assesment: Special Types of Life Cycle Assesment. Springer.

[15] Goodfield, D., M. Anda, G. Ho, 2014. Carbon neutral mine site villages: Myth or reality?. Renewable Energy. 66, pp. 62-68.

[16] Guereca L.P., N. Torres, C.R.J. Lopez, 2015. The CoProcessing of Municipal Waste in a Cement Kiln in Mexico, 
A Life-cycle Assesment Approach. Journal of Cleaner Production. 107, pp. 1-8.

[17] Haidar, 2015. Optimalisasi geometri peledakan pada Bench 450, Quarrry D. Indocement, Citereup.

[18] Harjanto, T.R., M. Fahrurrozi, I.M. Bendiyasa, 2012. Life Cycle Assesment Pabrik Semen PT. Holcim Indonesia Tbk. Pabrik Cilacap: Komparasi antara Bahan Bakar Batubara dengan Biomassa. J. Rekayasa Proses. 6(2), pp. 51-58.

[19] Hasanbeigi A., H. Lu, C. Williams, L. Price, 2012 International Best Practice for Pre-Processing and Orlando Co-Processing Municipal Solid Waste and Sewage Sludge in Cement Industry. Ernest Lawrence Berkeley National Laboratory, California.

[20] Johnson, E., 2009. Goodbye to carbon neutral: Getting biomass footprint right. Enviromental Impact Assesment Review. 29, pp. 165-168.

[21] Kajaste, R., dan M. Hurme, 2016. Cement industry greenhouse gas emmisions - managament options and abatement cost. Journal of Cleaner Production. 112(5), pp. 4041-4052.

[22] Lestari, F., 2010. Efektivitas pengelolaan kualitas lingkungan fisik pada industri semen pasca implementasi AMDAL dan ISO 14001. AGRIPLUS. 20, pp. 126-132.

[23] Li, C, Z. Nie Nie, S. Cui, X. Gong, Z. Wang, 2014. The life cycle inventory study of cement manufacture in China. Journal of Cleaner Production. 72, pp. 204-201

[24] Li, Y., H. Wang, J. Zhang, J. Wang, L. Ouyang, 2012. The Industrial Practice Of Co-Processing Sewage Sludge In
Cement Kiln. Procedia Enviromental Sciences. 16, pp. 628632.

[25] Reza, B., A. Soltani, R. Ruparathna, R. Sadiq, K. Hewage, 2013. Environmental and economic aspects of production and utilization of RDF as alternatif fuel in cement plants: A case study of Metro Vancouver Waste Management. Resource, Conservation, and Recycling. 81, pp. 105-114.

[26] Santoso, W., 2015. Perkembangan Industri Semen Indonesia. ASI, Bali.

[27] Setiawati, A., S.C.A. Prasetyo, J.U.D. Hatmoko, A. Hidayat, 2015. Kuantifikasi Emisi Gas $\mathrm{CO}_{2}$ Ekuivalen pada Konsentrasi Jalan Perkerasan Kaku. Jurnal Karya Teknik Sipil. 4(1), pp. 83-92.

[28] Stafford, F.N., M.D. Viquez, J. Labrincha, D. Hotza, 2015 Advances and Challenge for the Co-Processing in Lati American Cement Industry. Procedia Material Science. 9, pp. 571-577.

[29] Talahatu, M.A., A.E. Abdullah, 2013. Perancangan Galangan Kapal Boat Sistem Vacuum Infusion. FT UI, Depok.

[30] Wahyu, D., R. Sumiati, 2009. Analisa energi pada sistem rotary kiln unit Indarung IV, PT. Semen Padang. Jurnal Teknik Mesin. 6(2), pp. 79-91.

[31] Wiloso, E.I., R. Heijungs, G. Huppes, K. Fang, 2016. Effect of Biogenic Carbon Inventory on the Life Cycle Assesment of Bioenergy: Challenges to Neutrality Assumption. Journal of Cleaner Production. 125, pp. $18-85$ 